\title{
Comentário
}

\section{Bad boys, bad men}

Antisocial personality disorder (ASP) gets little respect. One of the best-validated disorders in the DSM-IV, ASP is rarely diagnosed, researched, or offered treatment. ${ }^{1}$ The lack of interest shown by psychiatrists and researchers is puzzling because the disorder is of enormous importance. It is highly prevalent, and produces tremendous suffering in individuals, families, and society at large. ASP is also associated with increased health care services utilization, early mortality, and poor treatment response in those suffering major depression or substance abuse disorders. Though the direct and indirect costs have never been estimated, yet ASP should be among the most costly disorders, primarily because of downstream costs of maintaining the criminal justice and penal systems. (The majority of criminals meet the diagnostic criteria for ASP.)

Psychiatrists and other mental health professionals frequently misunderstand the nature of ASP. Perhaps Goodwin and Guze, ${ }^{2}$ provided the best short definition for that: "Sociopathy (sociopathic personality or antisocial personality) is a pattern of recurrent, delinquent, or criminal behavior that begins in early childhood or early adolescence and is manifested by disturbances in many areas of life: family relations, schooling, work, military service, and marriage" (p. 240). The diagnosis of ASP relies on the mental health professional's ability to reveal this pattern and trace it through a patient's life. Isolated misdeeds or those confined to one area of life - work, for instance - are not per se evidence of ASP, though they may be clues to an underlying pattern of antisocial acts and attitudes. In short, ASP is a disorder of recurrent, lifelong misbehavior.

The public has long misunderstood the disorder, perhaps because of confusion about the term antisocial itself. In a psychiatric context, the term antisocial has nothing to do with a person's ability to socialize, and it is not used to describe those who are shy, inhibited, or reclusive. Rather, it implies a rebellion against society, a denial of the obligations that tie individuals to one another. The public is largely unaware of these distinctions, and are often more familiar with the older terms sociopathy and psychopathy.

I have recently attempted to bring attention to this neglected disorder. In writing Bad Boys, Bad Men, ${ }^{1}$ I envisioned the book would help educate the public and attract attention to ASP. I had naively hoped it might provoke a national debate on the issue. The book was based on my personal experiences as a psychiatrist working in an inpatient setting, and as a researcher. In the latter role, I have conducted a long-term follow-up of men with ASP admitted to the University of Iowa Psychiatric Hospital between 1945 and 1970. The study, which has been largely published, ${ }^{3-5}$ is one of the few such studies ever conducted. The findings were mostly consistent with earlier work by Robins $^{6}$ and Gluecks. ${ }^{7}$ Not only does the disorder persist for decades, but it is associated with substantial impairment with respect to psychiatric, social, and occupational adjustment. The strongest predictors of functioning at follow-up were severity at baseline, age, length of follow-up, and existing alcoholism. ${ }^{8}$ In short, those who did well were older, had less severe symptoms, had less recent hospitalizations, and were not currently drinking. There may be some truth to the notion that $1 \%-2 \%$ of antisocial individuals remit each year.

The individuals were very difficult to find. They had moved frequently, took on aliases, and seemed to deliberately frustrate any attempt to locate them. Several were quite unpleasant, and one nearly assaulted one of the researchers. Family members interviewed during the research gave us indelible impressions just how troublesome their relative was ("I don't care where he is. I never want to see him again."). Several men were found to be in prison and, of 71 individuals, 4 were murderers, one the notorious serial killer John Wayne Gacy, executed in 1994.

The book is filled with anecdotes as well as advice for family members and the antisocial individuals themselves. To the antisocial individual determined to change, I recommend the following:

- Accept your ASP

- Do not use ASP as an excuse to get into more trouble

- Use ASP as a reason to seek help

- Accept that ASP is a lifelong disorder

- Acknowledge that ASP has affected your family

- Try to control your temper

- Learn to feel guilt and shame

- Resist dwelling on the past

- Seek help for other problems (e.g., depression, alcoholism) as well

- Stop abusing those around you

- Be patient with therapy

One of the most discouraging facts I discovered in the process of writing the book is that there have been no randomized, controlled treatment trials on ASP. Thus, the therapeutic nihilism, which affects most mental health professionals' views of ASP treatment in unjustified; the question of treatment has never been adequately addressed. Therefore, it cannot be concluded that ASP is untreatable.

The book ends on a hopeful note. I urge the psychiatric community to work with, not shun, these unfortunate patients, and to develop creative ways to manage this difficult disor- 
der. Mental health professionals must overcome their own resistance to working with antisocial individuals if they are to develop new treatment and prevention strategies. Such work requires dedication, perseverance, and a deep understanding of the disorder. Short-term rewards may be less satisfying than those to be gained from treating other types of patients but all those working to treat mental illnesses should remain focused on the long-term goals as well. Our success in preventing and treating ASP will have a broad impact that ripples through society, helping to reduce spousal abuse, family violence, and criminal behavior.

A full range of treatments, including drug treatment and psychotherapy, need to be developed, tested, and refined. Lithium and dilantin have been shown to be effective in controlled trials conducted in aggressive prisoners, many of whom were undoubtedly antisocial individuals. Small, open-label studies and case reports of violent patients with other disorders suggest that aggression itself may respond to medication. Aggression, however, is only one symptom of ASP, and it is unlikely that drug treatment by itself will target the entire disorder. Other drugs, including serotonin reuptake inhibitors and atypical antipsychotics, ought to be investigated as well. Cognitive

\section{References}

1. Black DW. Bad Boys, Bad - Confronting antisocial personality disorder. New York: Oxford University Press; 1999.

2. Goodwin D, Guze S. Psychiatric diagnosis. $4^{\text {th }}$ ed. New York: Oxford University Press; 1989.

3. Black DW, Baumgard CH, Bell SE. A 16-to 45-year follow-up of 71 males with antisocial personality disorder. Compr Psychiatry 1995;36:130-40.

4. Black DW, Baumgard CH, Bell SE. The long-term outcome of antisocial personality disorder compared with depression, schizophrenia, and surgical conditions. Bull Am Acad Psychiatry Law 1995;23:43-52.

5. Black DW, Baumgard CH, Bell SE, Kao C. Death rates in 71 men with antisocial personality disorder: Comparison with general population mortality. Psychosomatics 1996;37:131-6. behavioral therapy, so helpful for a tremendous variety of conditions, is promising, but there is a need of considerable work to improve it to meet the demands of this population.

Research priorities should include wide-ranging projects to explore the origins of ASP and search for methods to change its course. Geneticists should continue to investigate the mechanisms behind the hereditary transmission of the disorder, locating genes that might predispose individuals to ASP and determining how these genes function at a molecular level. Following Raine et al's ${ }^{9}$ steps, neuroscientists should work to isolate brain regions or networks linked to antisocial behavior while identifying the biochemical and physiologic pathways that influence its expression. Lastly, the attention should be on the group at highest risk of developing ASP - namely, children with a behavior disorder. Improved understanding of their domestic life and social environment may eventually lead to more effective interventions to prevent ASP from developing.

Donald W Black Faculdade de Medicina da Universidade de Iowa. Iowa, EUA

6. Robins LN. Deviant children grown up. Baltimore: Williams \& Wilkins; 1996.

7. Glueck S, Glueck E. Unraveling juvenile delinquency. Cambridge: Havard University Press; 1951.

8. Black DW, Monahan P, Baumgard CH, Bell SE. Predictors of longterm outcome in 45 men with antisocial personality disorder. Am Clin Psychiatry 1997;9:211-6.

9. Raine A, Lencz, Bihrle S, LaCasse L, Colletti P. Reduced prefrontal gray matter volume and reduced autonomic activity in antisocial personality disorder. Arch Gen Psychiatric 2000;57:119-27. 